\title{
KONSEP PELESTARIAN LINGKUNGAN DALAM UPACARA TUMPEK WARIGA SEBAGAI MEDIA PENDIDIKAN BAGI MASYARAKAT HINDU BALI
}

\author{
I Ketut Sudarsana \\ Institut Hindu Dharma Negeri Denpasar. \\ E-mail: iketutsudarsana@ihdn.ac.id
}

\begin{abstract}
Environment is a place close to the existence of human life, but the environment also has significance for humans. With the physical environment man can use it to meet his material needs, with the human biological environment to meet his physical needs, and with his social environment man can meet his spiritual needs. This research has found that Tumpek Wariga as the local wisdom of the Balinese Hindu community is not an offering for plants, but a ceremony made, presented to the Lord. This means the ceremony is to express God's gratitude. The implementation of the ceremony Tumpek Wariga provides education to all Hindus of the importance of conservation, especially the preservation of plants.
\end{abstract}

Keywords:

Environmental Conservation, Tumpek Wariga, Education, Bali Hindu Society

\begin{abstract}
Abstrak
Lingkungan merupakan tempat yang dekat dengan keberadaan kehidupan manusia, selain itu lingkungan juga memiliki makna penting untuk manusia. Dengan lingkungan fisik manusia bisa menggunakannya untuk mencukupi kebutuhan materilnya, manusia dapat memenuhi kebutuhan jasmaninya dengan lingkungan biologi, dan manusia dapat memenuhi kebutuhan spiritualnya dengan lingkungan sosialnya. Penelitian ini berhasil menemukan bahwa Tumpek Wariga sebagai kearifan lokal masyarakat Hindu Bali bukanlah persembahan bagi tumbuh-tumbuhan, melainkan upacara yang dibuat, dihaturkan (dipersembahkan) kehadapan Tuhan. Artinya upacara ini adalah untuk mengucapkan rasa syukur Tuhan. Pelaksanaan upacara Tumpek Wariga memberikan pendidikan pada seluruh umat Hindu akan pentingnya pelestarian, khususnya pelestarian tumbuh-tumbuhan.
\end{abstract}

Kata Kunci:

Pelestarian Lingkungan, Tumpek Wariga, Pendidikan, Masyarakat Hindu Bali

\section{A. PENDAHULUAN}

Bali tidak bisa terlepas dari upacara-upacara adat dan keagamaan, yang menyebabkan Bali mempunyai pesona yang bisa membuat orang tertarik dan terkagum. Pulau Bali di kenal sebagai daerah pariwisata dikarenakan adat istiadat dan budayanya. Masyarakat Bali tidak luput dari upacara Yajna (persembahan tulus iklas) hampir setiap hari, orang Bali selalu melaksanakan yajna dari yang paling sederhana sejumput nasi setelah memasak, sampai pula Tawur atau Caru Ekadasa Rudra yang di laksanakan seratus tahun sekali, semua bahan yajnya tersebut dahulunya berasal dari hasil pertanian di Bali yang di persembahkan kepada Tuhan sebagai wujud rasa bhakti.

Adi Putra (Udayana, 2008:9-10) menyebutkan bahwa sebagian dari ritual atau upacara-upacara tersebut menghadirkan segala jenis pohon sebagai sarananya, meskipun sarana tersebut tidak mutlak adanya, namun hal itu tidak terlepas dari peradaban manusia, yang tidak dapat dilepaskan dari keberadaan pohon atau tumbuh-tumbuhan. Manusia dan kehidupan, tampaknya tidak terpisahkan dari keberadaan tumbuh-tumbuhan, dari dahulu hingga kini. Tumbuh-tumbuhan mengambil peran sebagai teman hidup dan memberi beraneka manfaat bagi manusia, bukan sebagai sebuah panggilan takdir untuk sebuah keaneka ragaman hayati. 
Ada serangkaian bukti yang menggambarkan kedekatan manusia dan alam. Peninggalan prasejarah meninggalkan bukti pahatan berbentuk pepohonan di gua-gua, bahkan terukir di relief-relief candi. Kehadiran pepohonan bahkan termuat dalam buku-buku suci (agama) yang umumnya dihadirkan sebagai pohon suci. Pohon suci memang dapat dijumpai pada jaman prasejarah. Ketika sejarah umat manusia mulai ditemukan, mulai dikenalnya sebuah tulisan, kepercayaan kepada binatang-binatang mitos tetap berlangsung (Sukmono, 1973:86).

Dalam konsep keharmonisan alam (Tri Hita Karana) dijelaskan adanya Parhayangan yang berarti menjaga hubungan yang harmonis dengan sang pencipta atau Tuhan Yang Maha Esa, kemudian ada yang disebut dengan Pawongan yang berarti menjaga hubungan yang harmonis dengan semua mahluk hidup dan yang terakhir adanya Palemahan yang berarti menjaga hubungan yang harmonis dengan alam lingkungan. Kemudian dari ketiga konsep keharmonisan tersebut dapat ditelusuri konsep yang ketiga yaitu, menjaga keharmonisan dengan alam lingkungan (Palemahan), yang dikenal di Bali dengan nama upacara Tumpek. Tumpek merupakan salah satu dari sekian banyaknya hari raya agama Hindu yang berdasarkan pawukon (wuku), yang dirayakan setiap enam bulan sekali (210 hari) yaitu setiap hari sabtu kliwon dengan wukunya masing-masing yang berganti-ganti setiap bulan atau 35 hari. Berdasarkan pengertian dan jenis wukunya itu, maka dalam waktu enam bulan itu umat Hindu akan merayakan tumpek selama enam kali, yang masing-masing memiliki tujuan nama, dan jenis yang berbedabeda, sesuai dengan jenis keenam Tumpek yang ada di Bali (Arwati, 2003:5).

Bahwa di dalam pelaksanaan hari Tumpek Wariga tersebut manusia sangat penting untuk melestarikan lingkungannya. Pelestarian terhadap lingkungan harus dipandang sama pentingnya dengan pelestarian keberadaan manusia itu sendiri. Jika sejak awal manusia mengembangkan esensi dari perayaan hari Tumpek Wariga ini, maka niscaya tidak akan ada bencana alam di muka bumi ini. Alam lingkungan harus dihargai, disayangi, seperti manusia menyayangi dirinya sendiri karena pepohonan juga adalah ciptaan dari Tuhan yang patut disyukuri oleh manusia itu sendiri. Menyayangi dan melindungi keberadaan tumbuh-tumbuhan adalah sikap dan sifat manusia yang amat mulia. Walaupun dalam tingkatan kesadaran manusia biasa, manusia juga diberikan kuasa untuk menebang atau memanfaatkan pepohonan itu untuk dipergunakan dalam kehidupan.

Di samping hari Tumpek Wariga, terdapat juga lima jenis Tumpek yang lain dalam harihari raya Hindu di Bali yaitu : 1. Tumpek Landep yakni upacara selamatan untuk senjata, 2. Tumpek Wariga selamatan untuk tumbuh-tumbuhan, 3. Tumpek Kuningan selamatan untuk gamelan, 4. Tumpek Klurut selamatan untuk unggas, umumnya upacara selamatan untuk unggas ini digabungkan pada hari Tumpek Uye ini, 5. Tumpek Uye atau Tumpek Kandang yakni upacara selamatan untuk binatang periaraan, 6. Tumpek Wayang yakni upacara selamatan untuk Wayang.

Lontar Sundarigama yang memberikan petunjuk mengenai hari-hari raya Hindu di Indonesia mengungkapkan : Hari Tumpek Kandang ialah upacara selamatan untuk binatang-binatang, binatang yang disembelih dan binatang piaraan, hakekatnya ialah untuk memuja Tuhan Yang Maha Esa, Siwa yang disebut Rare Angon, penggembala makhluk. Bersandarkan kutipan ini, tegas bahwa yang dipuja ialah Tuhan Yang Maha Esa, bukan memuja binatang, demikian pula terhadap senjata-senjata, tumbuh-tumbuhan, gamelan dan lain sebagainya. Dalam ajaran agama Hindu, keharmonisan hidup dengan semua makhluk dan alam semesta senantiasa diamanatkan.

Manusia hendaknya hidup harmonis dan selaras dengan alam semesta, khususnya bumi dan dengan ciptaan-Nya yang lain, terliput binatang dan tumbuh-tumbuhan. Di dalam ajaran Hindu, seluruh makhluk diyakini mempunyai jiwa yang berasal dari Tuhan Yang Maha Esa. Doa umat Hindu sehari-hari (dalam Puja Tri Sandhya bait ke-5) dengan gamblang menyatakan : Sarvaprani 
hitankarah (hendaknya semua makhluk hidup sejahtera) ialah doa yang bersifat universal atau umum bagi keseimbangan jagat raya dan segala isinya. Upacara selamatan kepada tumbuh-tumbuhan dimaksudkan untuk menumbuhkan rasa kasih sayang kepada alam, khususnya tumbuh-tumbuhan.

\section{B. METODE}

Penelitian ini merupakan jenis penelitian kualitatif, dikatakan demikian sebab hasilhasil dari semuannya tak didapatkan melalui prosedur statistik atau pun hitungan lainya. Penelitian ini bukan membutuhkan rangkaian angka-angka tetapi lebih banyak membutuhkan jenis data yang berbentuk rangkaian kata-kata. Prosedur penelitian ini menghasilkan data deskriptif berupa lisan, kata-kata tertulis, dan prilaku orang-orang yang dapat diamati. Jenis data kualitatif yang diperoleh bersumber dari data primer dan data skunder

Penentuan informan dalam penelitian ini menggunakan teknik Purposive Sampling, yang merupakan teknik penentuan informan dengan akurasi dapat memberikan data yang diperlukan sesuai dengan tujuan peneliti. Metoda pengumpulan data dalam penelitian ini adalah wawancara, observasi, dan pencatatan dokumen dengan analisis data dilakukan melalui tiga jalur kegiatan yaitu : 1) data reduction (reduksi data), 2) data display (penyajian data), 3) conclusion drawing (verifikasi).

\section{HASIL DAN PEMBAHASAN}

\section{Upaya Mengharmoniskan Alam Semesta Menuju Pelestarian Lingkungan}

Hidup harmonis ialah dambaan bagi setiap umat manusia, hubungan yang harmonis dalam pandangan Hinduisme dijabarkan dengan konsep Tri Hita Karana. Filosofis Tri Hita Karana ialah kebahagian hidup batin dan lahir yang disebabkan oleh hubungan yang seimbang dan harmonis antara manusia dengan manusia, manusia dengan Tuhan, dan manusia dengan lingkungan, substansi dan nilai yang terkandung didalamnya sangat luas dan tidak pernah mengalami degradasi oleh perkembangan zaman. Konsep Tri Hita Karana mengajarkan kepada umat Hindu mengenai pendekatan yang digunakan untuk mencapai tujuan. Selanjutnya, bertolak daro konsep Trihita karana (tiga penyebab kebahagian). Apabila ada kesenjangan antara ketiganya maka akan menimbulkan suatu yang tak diinginkan oleh manusia. Dalam hal ini tujuan pemujaan mengandung pengertian adanya keharmonisan dengan alam beserta isinya, Filosofis Tri Hita Karana bersifat universal dalam artian dapat diterapkan oleh semua manusia yang mendambakan kebahagiaan dalam kehidupannya. Tujuan akhir dari hubungan yang seimbang dan harmonis antara manusia dengan manusia, manusia dengan Tuhan, dan manusia dengan lingkungannya adalah kesejahteraan alam semesta beserta isinnya. Hubungan yang harmonis antara manusia dengan lingkungan terlebih dengan alam semesta ini diterapkan dengan upacara Tumpek Wariga yang merupakan salah satu dari sekian upacara yang ada di Bali. Upacara Tumpek Wariga ini berupaya untuk mengharmoniskan alam semesta beserta isinnya.

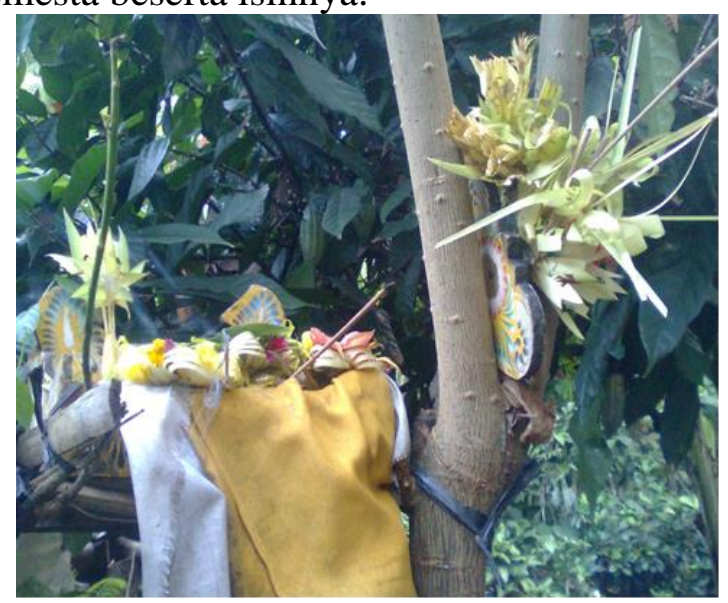

Gambar 1: Bentuk upacara Tumpek Wariga

Melalui upacara tersebut diharapkan keharmonisan tetap terjaga berdasarkan konsep Tri Hita Karana, hubungan yang harmonis terhadap Tuhan, hubungan yang harmonis terhadap sesama mahkluk hidup, dan hubungan yang harmonis terhadap lingkungan sekitar akan senantiasa terjaga dan tetap bertahan. Upacara Tumpek Wariga dilaksanakan pada saniscara Keliwon Wuku 
Wariga sebagaimana yang disebutkan dalam salinan lontar Sundari Gama sebagai berikut :

"Wariga Saniscara Kliwon, ngaran panguduh pujawali Sanghyang Sangkara, apan sira amrtaken sarwaning tawuwuh, kayu-kayu kunang, widhi-widhanana, pras tulung, sesayut, tumpeng, bubur mwang tumpeng agung iwak nia guling bawi, itik wenang, saha raka, penyeneng, tetabuh, kalinggania anguduh ikang awoh mwang godong, dadya pamrtaning hurip ring manusa. Sesayut cakragni kalinggania anuduh kna adnyana sandhi."

Terjemahannya :

Wuku wariga yakni pada hari Saniscara Kliwon, disebutlah hari panguduh. Suatu hari untuk memuja Sanghyang Sangkara, sebab Beliaulah yang menciptakan segala tumbuh-tumbuhan termasuk kayu-kayuan. Adapun upakaranya ialah peras tulung sesayut, tumpeng bubur dan tumpeng agung dengan daging babi, atau itik diguling. Baik pula disertai dengan rakaraka (jajan dan buah-buahan), penyeneng, tetebus dan sesayut cakragni. Adapun bebanten tersebut di atas ialah mendoakan semoga atas rahmat Hyang Widhi maka segala tumbuh-tumbuhan dapat tumbuh subur, lebat buahnya bersusun-susun dan dapat dimanfaatkan untuk kehidupan manusia dalam ketentraman hati, serta kesejahteraan lahir dan bathin (Suandra, 1992 : 15).

Sesuai dengan salinan lontar di atas bahwasannya pada waktu wariga yaitu tepatnya pada Sabtu Kliwon merupakan memperingati otonan terhadap tumbuhtumbuhan. Masyarakat Hindu berdoa kepada Dewa Sangkara agar tumbuh-tumbuhan diberikan keselamatan dan kesuburan. Upacara ini memiliki makna tersendiri karena upacaranya untuk mendoakan tumbuhan yang pada saat itu sedang berbunga.

\section{Upacara Tumpek Wariga Sebagai Media Pendidikan Bagi Masyarakat Hindu Bali}

Ada banyak cara para leluhur umat Hindu dalam mewariskan nilai-nilai luhur agama Hindu yang bersifat global salah satu caranya adalah dengan cara mewariskan bentuk upacara keagamaan yang penuh mengandung nilai-nilai pendidikan agama. Diantara upacara keagamaan yang banyak jenisnya adalah upacara keagamaan yang dilaksanakan pada Tumpek Wariga. Dari segi kata "tumpek" menurut Sudarsana (2003 : 14), artinya dekat, atau hari suci, sebagai hari peringatan turun mendekatnya kekuatan Ida Sang Hyang Widhi. Pada hari rerainan Tumpek Wariga khususnya, yang diperingati sebagai pemujaan sarwa tumawah, merupakan peringatan akan melekatnya kekuatan Tuhan sebagai Dewa pelindung tumbuh-tumbuhan.

Momentum yang sangat tepat bagi umat Hindu untuk memuja Tuhan sebagai Dewa Sangkara/Dewa pelindung tumbuh-tumbuhan pelaksanaan upacara Tumpek Wariga sekaligus memberikan pendidikan bagi umat akan kebesaran Tuhan yang berada dimanamana, Tuhan berada di setiap tempat, WyapiWyapaka, termasuk juga Tuhan berada disetiap tumbuh-tumbuhan. Tuhan Yang Maha Esa yang berada dalam tumbuh-tumbuhan dalam kita Sveta Svatara Upanisad disebut Vanaspati selengkapnya kitab Sveta Svatara Upanisad 11.17 sebagai berikut :

$$
\begin{aligned}
& \text { yo devo gnah yo psu } \\
& \text { yo visvam bhuvana ma visesa } \\
& \text { yo osadhisu yo vanaspatisu } \\
& \text { jasmai devaya namo nama. }
\end{aligned}
$$

Terjemahananya :

Sujud bhakti pada Tuhan yang berada pada api, yang berada di air, yang meresapi seluruh alam semesta yang ada dalam tumbuhtumbuhan, yang ada dalam pohon-pohon kayu. (Tim Penyusun, 2003 : 32).

Sabda kitab Sveta Svatara Upanisad mengatakan tentang Tuhan dalam immanent atau Tuhan berada dimana-mana, di air, api dan pohon-pohon kayu, sangat dekat 
maknanya dengan pelaksanaan upacara Ngatag pada hari Tumpek Wariga.

Saat hari Tumpek Wariga difokuskan untuk memuja Tuhan dalam manifestasinya sebagai Dewa Sangkara atau pelindung tumbuh-tumbuhan. Pelaksanaan upacara Tumpek Wariga memberikan pendidikan pada umat Hindu tentang kemahakuasaan Tuhan, bahwa Tuhan berada di segala tempat, termasuk berada di tumbuh-tumbuhan.

Dalam wujud tindakan sehari-hari (Nitya Karma) pelaksanaan upacara Tumpek Wariga memberikan pendidikan pada seluruh umat Hindu akan pentingnya pelestarian, khususnya pelestarian tumbuh-tumbuhan. Pelaksanaan upacara Tumpek Wariga jika dicermati dan dilaksanakan sesuai dengan semangat Veda, dapat mencegah adanya penebangan hutan secara liar dan membabi buta (illegal logging). Pelaksanaan Tumpek Wariga pada hakekatnya bertujuan untuk melestarikan sumber daya hayati dari alam semesta, misalnya hutan yang masih terpelihara dengan baik dapat menjaga kestrabilan debit air dan mencegah timbulnya tanah longsor, karena kondisi tanah yang disangga oleh akar-akar pohon yang kuat dan menjalar di tanah.

Keadaan pepohonan yang lestari dan seimbang dengan keadaan luas tanah dapat pula mencegah kekeringan atau mencegah krisis air saat musim kemarau. Dengan demikian pelaksanaan upacara Tumpek Wariga berfungsi memberikan pendidikan pada umat akan pentingnya pelestarian tumbuh-tumbuhan agar tetap terjaganya keseltarian alam. Umat diharapkan memperlakukan alam dengan bersahabat dan manusia dilarang memperlakukan kekerasan pada alam. Dengan demikian, alam akan sangat ramah pada manusia dan memberi segala jenis kehidupan pada manusia.

Dalam kitab Reg Veda dinyatakan bahwa Tuhan menitipkan bumi ini kepada orangorang budiman, sehingga akan membalas dengan mencurahkan hujan, dan udara yang segar serta makanan yang cukup. Hal tersebut dinyatakan dalam kitab Reg Weda IV.25.6 sebagai berikut:
Aham bhunmi madada marryyayaham

vrstim

Disuse martaya ahamapo anayam vavasana

Mama devaso anu katamayan.

Terjemahan :

Aku memberikan bumi kepada orang-orang baik dan hujan serta udara untuk umat manusia, wahai para bijaksana, datanglah kehadapanku dengan keinginan yang penuh.

Orang-orang baik, akan memelihara alam dengan arif bijaksana, maka Tuhan akan memberi anugerahnya dengan hasil bumi yang melimpah dan dengan cuaca alam yang penuh persahabatan. Pelaksanaan upacara Tumpek Wariga adalah contoh perbuatan yang baik dari manusia terhadap alam dan tumbuhtumbuhan, tetapi masih bersifat serimonial formal. Tindakan yang berupa serimonial formal perlu ditindaklanjuti dengan perbuatan nyata dalam bentuk tindakan sehari-hari (Nitya Karma).

Berbicara tentang masyarakat dan budaya Bali yang beragama Hindu pada khususnya segala aktivitasnya dalam berbagai bentuk selalu diusahakan berlandaskan ajaran agama yang dianutnya, sehingga dikatakan sebagai suatu masyarakat yang religious. Sifat demikian secara nyata dapat dilihat dalam berbagai kegiatan atau usahanya dalam mencapai kebahagian yang abadi. Tujuan tersebut dalam agama hindu disebut Moksartham Jagadhitaya Ca Iti Dharma, artinya tujuan agama Hindu adalah untuk mencapai kesejahteraan didunia dan moksa. Untuk mencapai tujuan tersebut, maka perlu diadakan pendidikan baik dibidang jasmani maupun mental spiritual sehingga terwujudlah tujuan yang ingin dicapai. "Salah satu cara pendidikan dibidang mental spiritual yaitu melalui pelaksanaan yadnya"(Surayin, 2004:9).

Didalam Upadesa disebutkan tiga kerangka dasar agama Hindu yaitu: "tatwa, etika dan upacara. Ketiga kerangka dasar ini dilaksanakan dalam kehidupan beragama demi terwujudnya suatu kehidupan yang mantap, serasi dan seimbang serta terpeliharanya suatu 
kerukunan hidup beragama. Seiring dengan maksud diatas dalam prakteknya dimasyarakat khususnya di Bali, yang paling menonjol adalah upacara (ritual) dan tercetus dalam bentuk korban suci yang disebut yadnya. Pelaksanaan yadnya atas dasar adanya Tuhan mengawali penciptaan dunia beserta isinya berdasarkan yadnya. Jadi yadnya bermula dari Tuhan patut diteruskan agar kehidupan didunia ini berlanjut terus dengan saling beryadnya.

Konsep agama Hindu adalah mewujudkan antara manusia dengan manusia, manusia dengan Tuhan, dan manusia dengan lingkungannya. Di Bali tiga keseimbangan itu disebut dengan Tri Hita Karana, artinya tiga faktor yang menyebabkan terwujudnya suatu kebahagiaan (Arwati, 2007:4). Kehidupan manusia dimuka bumi ini selalu dihadapkan pada permasalahan yang rumit dan kompleks. Manusia hidup dialam dan dari hasil alam, oleh sebab itu manusia patut menjaga dan memelihara hubungan yang harmonis antara manusia (Bhuana Alit) dan alam (Bhuana Agung) secara lahir dan bathin.

Manusia tidak dapat hidup sendiri sangat tergantung pada alam, sesama manusia, dan Sang Pencipta. Munculnya berbagai kejadian yang aneh pada alam, sangat mempengaruhi kehidupan makhluk-makhluk hidup di dunia ini, sehingga manusia yang berperan sebagai subyek sekaligus obyek perasaannya terganggu, cemas, ragu-ragu, takut dan kurang menentu. Ketidak harmonisan bermunculan akibat adanya berbagai masalah, antara lain muncul dari pemikiran, perkataan, dan perbuatan manusia, sehingga alam, manusia, dan sampai tempat suci sthana-Nya Tuhan ikut tercemar, dilain pihak ada pengaruh dari pergantian musim (Panas kehujan dan sebaliknya) menimbulkan pengaruh yang buruk pula terhadap kehidupan semua makhluk hidup didunia ini. Untuk memilahmilah berbagai permasalahan yang dihadapi akibat adanya ketidak harmonisan itu, maka upaya awal untuk menetralisir perlu diupayakan oleh manusia selain secara nyata melalui usaha-usaha sekala, dan secara niskala melalui pelaksanaan upacara ritual, yaitu memohon kembali kehadapan Sang Pencipta selaku sumber-Nya untuk memohon anugrah keselamatan untuk tumbuh-tumbuhan agar terhindar dari segala jenis penyakit.

\section{SIMPULAN}

Umat Hindu melaksanakan Upacara Tumpek Wariga atas petunjuk kitab Sundarigama dan sesuai pula dengan kitab suci Veda. Bahwa manusia sangat tergantung pada alam semesta, khususnya pada tumbuhtumbuhan, karena itu manusia sebagai makhluk yang percaya pada Tuhan sebagai Maha Pencipta, patut bersyukur dan mohon kepada Tuhan sebagai pencipta tumbuhtumbuhan, diharapkan beliau memberi anugerahnya agar melimpahkan amerta melalui segala tanem tuwuh. Upacara Tumpek Wariga terus dilaksanakan dan dilestarikan karena diyakini dengan melaksanakan upacara ini bisa selalu dekat dengan Tuhan dan melalui upacara ini masyarakat bisa menyampaikan rasa terima kasihnya terhadap tumbuh-tumbuhan karena tanpa adanya tumbuh-tumbuhan manusia tidak bisa melangsungkan kehidupan di dunia ini.

Melalui pelaksanaan Upacara Tumpek Wariga sekaligus memberikan pendidikan bagi umat akan kebesaran Tuhan yang berada dimana-mana, Tuhan berada disetiap tempat, Wyapi-Wyapaka, termasuk juga Tuhan berada disetiap tumbuh-tumbuhan.

\section{DAFTAR PUSTAKA}

Arwati, N. M. S. (2003). Hari Raya Tumpek. Denpasar : Upada Sastra.

Arwati, N. M. S. (1996) Upacara-Upakara Agama Hindu Berdasarkan Pawukon. Denpasar : Upada Sastra.

Bakker, A. (1995). Kosmologi dan Ekologi. Yogyakarta : Kanisius.

Donder, I K. (2007). Kosmologi Hindu : penciptaan, pemeliharaan, dan peleburan, serta penciptaan kembali alam semesta. Surabaya: Paramita.

Januariawan, G. (2004). Konsep Pelestarian Lingkungan dalam Sastra Agama Hindu Dan Penerapannya Dalam Masyarakat Bali. Denpasar: STAHN Denpasar. 
Sudarsana, I. K. (2017). Interpretation Meaning of Ngaben for Krama Dadia Arya Kubontubuh Tirtha Sari Ulakan Village Karangasem District (Hindu Religious Education Perspective). Vidyottama Sanatana: International Journal of Hindu Science and Religious Studies, 1(1), 1-13.

Sudartha, T. R., dan Atmaja, I. B O. P. (2005). Upadesa Tentang Ajaran-ajaran Agama Hindu, Surabaya : Paramita
Pudja, G. (1999). Bhagawadgita (pancama veda). Surabaya : Paramita.

Titib, I M. (2001). Teologi \& Simbol-simbol Dalam Agama Hindu. Surabaya : Pāramita.

Wiana. I K. (2006). Menyayangi Alam Wujud Bhakti Pada Tuhan. Surabaya: Paramita.

Wiana. I K. 2007, Tri Hita Karana, Menurut Konsep Hindu, Surabaya : Paramita. 